\title{
Successful overwintering of arthropods in roadside verges
}

\author{
André P. Schaffers • Ivo P. Raemakers • \\ Karlè V. Sýkora
}

Received: 24 December 2010/Accepted: 13 September 2011/Published online: 25 September 2011

(C) The Author(s) 2011. This article is published with open access at Springerlink.com

\begin{abstract}
In densely populated areas, roadside verges often provide the last semi-natural habitats available. Their ecological value is often stressed by bio survey results. Yet insect summer surveys potentially misjudge the value of a biotope (roadside or otherwise) since the occurrences of species may only be seasonal, or even transient. To effectively ascertain the importance of a site for insects, species must be shown to complete their life cycle there or at least be shown to successfully accomplish critical life stages, such as reproduction or overwintering. To confirm overwintering of arthropods in roadsides, sods were cut in late winter in a verge where several years of summer survey data were available. The sods were placed in transparent semi-permeable cages and kept alive during subsequent spring, summer and autumn. All emerging arthropods were caught inside the cages using pitfall and funnel traps and identified to order or family level. Most of the terrestrial arthropod phyla and orders occurring in NW-Europe appeared to be represented. Several groups were further identified to the species level: Carabidae (Coleoptera), Curculionidae (Coleoptera), Araneae, Orthoptera, Apidae (Hymenoptera), Syrphidae (Diptera) and Dephacidae/Cercopidae (Hemiptera). Particularly for the Carabidae, Araneae and Curculionidae, many species recorded in summer were also found to overwinter; species overlap amounted to approximately $67 \%$. Rarefaction of the summer sample or excluding possible summer vagrants, raised this overlap to as much as $88 \%$ for the Carabidae. Many of the species successfully overwintering in the roadside verge were generalists, but less
\end{abstract}

A. P. Schaffers $(\varangle) \cdot$ I. P. Raemakers · K. V. Sýkora Nature Conservation and Plant Ecology Group, Department of Environmental Sciences, Wageningen University, PO Box 47, 6700AA Wageningen, The Netherlands

e-mail: andre.schaffers@wur.nl common, more stenotopic species were present as well. Not only species hibernating as adults were involved, but also species overwintering in immature stages, indicating reproduction also takes place in the roadside verge. Apparently the roadside occurrence of many arthropod species, including stenotopic and declining ones, is not merely seasonal or incidental, and roadside verges do not necessarily act as a sink only. The ecological importance often attributed to roadside verges should clearly be taken seriously.

Keywords Hibernation - Life cycle - Insect bio-survey . Carabidae Curculionidae Araneae Conservation value . Grassland

\section{Introduction}

In many areas intensifying agriculture and ongoing urbanisation has resulted in considerable habitat loss for wildlife (Stoate et al. 2001; Geiger et al. 2010). In such landscapes roadside verges provide remaining (or sometimes even the last) semi-natural habitat for various organisms, especially arthropod and plant species (Way 1977; Dowdeswell 1987; Munguira and Thomas 1992; Sýkora et al. 1993; Vermeulen 1993; Eversham and Telfer 1994; Samways et al. 1997; Ries et al. 2001; Le Viol et al. 2008; Noordijk et al. 2009). Roadside verges also connect habitats and may thus function as corridors or steppingstones in colonisation and meta-population processes (DeMers 1993; Vermeulen 1994; Noordijk 2009). These actual and potential values of roadside verges are widely recognised and in several countries policies and management schemes have been developed to conserve or enhance this ecological function (Anonymus 1984; Zwaenepoel 1998; RWS 2004; Keizer et al. 2006). 
Yet, it is difficult to actually demonstrate the arthropod conservation value of individual roadside verges. Bio-surveys and arthropod assessments are usually carried out in spring or summer and focus almost exclusively on adult specimens (e.g. Ries et al. 2001; Koivula et al. 2005; Le Viol et al. 2008; Schaffers et al. 2008; Noordijk et al. 2009; Kotze et al. 2011). The results of such surveys do not unequivocally reveal the site's contribution to the survival of the encountered species. Many arthropods are quite mobile and their ecology is poorly known (Dennis et al. 2007; Samways et al. 2010). The roadside occurrence of many arthropods, stenotopic species in particular, might just be seasonal or transient, with actual survival depending on the surrounding landscape (Thomas et al. 2001). Seasonal occurrence of arthropods has previously been described for farmland, where the long-term survival of most arthropods depends on field margins rather than on the fields themselves (Sotherton 1984, 1985). Vagrancy is a known problem in for instance butterfly recording schemes, leading to misjudgements of species statuses (Dennis 2001). In some situations it is even conceivable that roadside verges act as a habitat sink (Pulliam 1988; Vermeulen 1994; Eversham and Telfer 1994; Ries et al. 2001; Koivula 2005; Desender et al. 2010). Especially when roadside verges are attributed conservation objectives, it is important to gain a better understanding of their actual importance for arthropods.

To ascertain that roadside verges are truly important-i.e. to show that arthropods actually complete their life cycle in those habitats-is not easy. A multitude of species with a wide variety of life-strategies is involved. However, in temperate climates the life cycle of most arthropods shows a distinct annual pattern, generally involving a winter diapause (Tauber and Tauber 1976; Thiele 1977; Leather et al. 1993; Speight et al. 2008). During this hibernation period, eggs and hibernating individuals cannot anticipate on changing circumstances. It is therefore of crucial importance for a species to find suitable locations where this life history stage (hence called overwintering) can be successfully completed. This may warrant the generalisation that if a species overwinters successfully in a specific roadside verge, this verge may be considered to provide a substantial contribution to its local survival. Comparing the overwintering species composition to the results of a common summer survey will lead to a better understanding of the actual conservation value of a site. If similar species compositions are found, then both survey methods apparently are suitable for arthropod conservation value assessment.

The aims of the present study were to ascertain arthropod overwintering in roadside verges and to assess the relevance of common spring/summer bio-surveys. The following three main questions will be addressed in this study:
(1) Do arthropod species use roadside verges for overwintering and can they successfully complete their life cycle in the year following?

(2) Do also rare species or those adapted to a narrow range of environmental conditions (stenotopic species) utilize roadside verges?

(3) To what extent is the species composition of overwintering arthropods related to the species composition in a common spring/summer bio-survey?

\section{Methods}

Study area

The study area concerned the roadside verge of a main road $(\mathrm{N}-225)$ near Heelsum, the Netherlands $\left(51^{\circ} 58^{\prime} 31.7^{\prime \prime} \mathrm{N}\right.$ $05^{\circ} 45^{\prime} 05^{\prime \prime} \mathrm{E}$ ). The vegetation consisted of a grass encroached Thero-Airion (Schaminée et al. 1996). This is a late stage pioneer community of dry, acid to neutral, base- and nutrient-poor sandy soils. Dominant and characteristic plant species were the grasses: Agrostis capillaris L. and Festuca filiformis Pourr., the herbs: Rumex acetosella L., Hypochaeris radicata L., Ornithopus perpusillus L., Jasione montana L., Teesdalia nudicaulis (L.) R.Br., and the mosses: Hypnum cupressiforme Hedw. and Polytrichum juniperinum Hedw. In the years before study, the verge had been mown every 2 or 3 years in autumn and hay was removed. The verge measured $30 \mathrm{~m}$ in width and the total area of the Thero-Airion community was about $750 \mathrm{~m}^{2}$. An extensively grazed pasture bordered the verge, but not the studied community.

\section{Assessment of overwintering arthropods}

In February 2001, 40 sods were cut in the roadside verge from an area of approx. 200-250 $\mathrm{m}^{2}$ within the TheroAirion vegetation. Individual sods measured $0.25 \times$ $0.50 \mathrm{~m}$ with a depth of $0.20 \mathrm{~m}$; the total surface of all collected sods therefore amounted to $5 \mathrm{~m}^{2}$.

The sods were placed in five 1 by $1 \mathrm{~m}$ cages, located on a ploughed field at Wageningen University. These cages (Fig. 1) in fact concern modified emergence traps, which are commonly used to assess soil- and litter-overwintering arthropods (Southwood and Henderson 2000). The soil below the cages was sandy like the sods themselves, though richer in nutrients and more humid. The vegetation in the cages was kept alive until October to give emerging immature arthropods the opportunity to reach adulthood. This way the problem of identifying juveniles, which is difficult if possible at all, was avoided. The vegetation in the cages was watered if necessary, but although the cage 


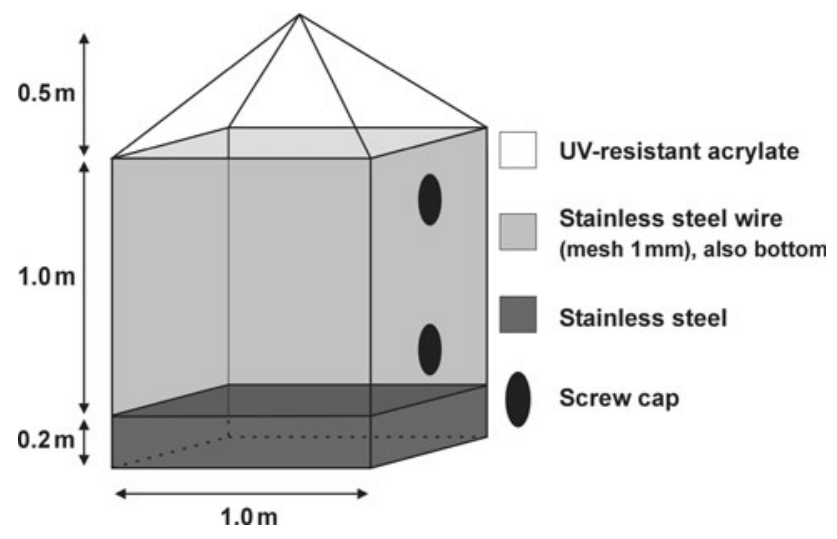

Fig. 1 Schematic drawing with dimensions of the cages used to asses overwintering of arthropods in sods taken from road verges

top was made of acrylate, the wire gauze sides and bottom admitted enough rain and moisture to make watering necessary only occasionally. According to measurements performed in November, light intensity in the cages was approximately $60 \%$ of full daylight.

Adult arthropods were collected in the cages from early March until the middle of October. Per cage we used one pitfall trap to catch ground dwelling arthropods and one funnel fall in the top of each cage to collect flying arthropods. The pitfall traps were opened 2-3 days per week and checked once or twice a day. With this intensive removal scheme we intended to keep predation levels within the traps low. Adult arthropods were collected for identification, but trapped juveniles were released again. Despite regular checking juveniles were sometimes killed or mutilated by predators. The funnel traps were installed in the middle of April and filled with a 4\%-formaldehyde solution for preservation. We aimed to catch full-grown, identifiable adults in these traps (assuming individuals must have been flying to enter these traps), but juveniles were nevertheless caught in the funnel traps occasionally and these individuals could not be released again. The following groups were identified to species level: Carabidae (Coleoptera), Curculionidae (Coleoptera), Orthoptera, Araneae, Syrphidae (Diptera), Apidae (Hymenoptera) and also the smaller groups Delphacidae and Cercopidae (both Hemiptera). Most other arthropods were identified to order or family level. Juveniles of the groups studied in detail could seldom be identified at species level and could only be included in total counts at higher levels.

Of the Araneae only epigeic, non-webbing species were considered. Webbing species were actively removed from the cages for two reasons: first of all they are very efficient predators and as such would heavily interfere with our trapping effort and secondly this group was also not sampled during the summer season bio-survey (see below) that was used to compare the winter data against.
For Carabidea we used two separate classifications for deciding whether or not a species should be considered stenotopic (for dry or wet habitats): an eurytopy measure of 5 or less in Turin (2000) or classification as stenotopic by Lindroth (1949).

The study did not include a null treatment to identify possible cage-invading species, even though the $1 \mathrm{~mm}$ wire gauze used for the cages most likely was not impenetrable for some very small, adult or juvenile, arthropods. However, the arthropod species composition of arable fields (on which the cages were placed) is known to be species poor and of quite a different nature than that of nutrient poor grasslands from which the sods originated (Sotherton 1984, 1985; Turin 2000), allowing most possible invaders to be recognized as such. With this in mind and with a fixed number of cages available, reducing the risk of revealing only a subset of the overwintering species (by using all cages) was considered more important than reducing the risk of inadvertently including potentially cage-invading 'arable' species (by assigning null treatments to one or more cages).

\section{Assessment of arthropods in summer}

The investigated roadside verge was part of a study concerning the relation between plant communities and invertebrate communities (Schaffers et al. 2008). For this study several arthropod taxa (the ones identified to species level mentioned before) were sampled during the growing seasons of 1998, 1999 and 2000, at the exact same roadside location and plant community where the sods were collected to assess overwintering. Carabidae and Curculionidae were collected from June to October 1998 and March to October 1999 using 5 pitfall traps $(\mathrm{d}=9 \mathrm{~cm}, 5 \mathrm{~m}$ interspaced, filled with a $4 \%$ formol solution, and sheltered under a lid to keep out rain) which were pooled. Pitfall data on Curculionidae was completed with data from sweepnet catches (see below). For Araneae, only the 1998 pitfall catches were used and only epigeic, non-webbing species were considered. Apidae were collected using an insect net and using white cups. For the latter so-called 'yellow pan method', three cups $(\mathrm{d}=9 \mathrm{~cm})$ filled with a $\mathrm{NaCl}$-solution were placed in the vegetation in May and August 2000, during 1 week of fair weather each time. Syrphidae were collected together with Apidae while the latter were the prime target. Orthoptera records were obtained by sound and sight observations, performed on various occasions with fair weather during 1998, 1999 and 2000. Cercopidae and Delphacidae (and additional Curculionidae, see above) were collected in 1998 and 1999 using a sweep net on four occasions each year. The combined result of these different sampling techniques were considered to reflect the arthropod composition of the site in the growing season. 
Data analysis and statistics

For arthropod groups where both winter and summer catches were available (the groups identified to species level), overwintering species composition was compared to the results of the summer survey. As a measure of similarity we used the percentage species overlap, calculated as the number of species shared, relative to the number of species in summer. In addition, also the Jaccard index and the Sørensen similarity coefficient can be calculated, defined as the number of shared species relative to the total or the average number of species, respectively. In the presenceabsence approach applied here the Sørensen similarity equals the one-complement of the Bray-Curtis dissimilarity (Legendre and Legendre 1998). We also calculated Spearman rank correlations between summer and winter abundances.

For a meaningful comparison between winter and summer catches, however, several aspects deserve attention. First, we need to address differences in sampling intensity. Summer sampling collects actively moving individuals and thus tends to effectively cover a wide area, whereas the winter sample was relatively small and collected over a fixed area. The summer survey thus resulted in the capture of much more individuals than obtained from the $5 \mathrm{~m}^{2}$ of sods cut in winter. We used rarefaction (Hurlbert 1971) to compensate for this. We rarefied the summer sample to the number of individuals caught in winter. The expected richness of the rarefied summer sample was calculated using the equations given by Hurlbert (1971). To assess the species overlap after rarefaction, we first ranked the summer catches according to species abundance and only retained the $k$ species with the highest number of individuals, with $k$ being the rarefied richness. If $k$ was a fractional number, or if the abundance of the $k$ th species was shared by others, interpolation was used to calculate the overlap.

As an alternative for rarefaction, we deleted possible summer vagrants from the summer data before calculating the overlap. Suspected vagrants were provisionally defined here as those species with less than four individuals in the entire summer sample, irrespective of the winter data.

Apart from these adjustments to the summer survey, we also need to ascertain that the winter survey was extensive enough to have recorded most of the overwintering species. To ascertain the comprehensiveness of the winter sample we studied the shape of rarefaction curves. We did not rarefy individuals but used rarefaction based on samples (the overwintering cages), thus allowing for sample heterogeneity. We determined the number of trapped species for all possible combinations of $0-5$ cages $(n=32)$. The so obtained rarefaction curves essentially correspond to species-area curves covering $0-5 \mathrm{~m}^{2}$ of soil sods.
Under the assumption that species numbers should level off with growing sample size, we tested the comprehensiveness of the sample by fitting both a linear and a logarithmic model to the rarefaction curve. If the fit of the exponential model turns out to little better than that of the linear model, sample size has likely not been sufficient since no obvious levelling-off can be detected in the rarefaction curve. If on the other hand the logarithmic model clearly fits the observations better, the species increase is apparently levelling-off within the $5 \mathrm{~m}^{2}$ of sods sampled and sample size may be concluded to have been more or less sufficient (depending on the amount of levelling-off).

Both models tested were required to pass through the origin $\left(0 \mathrm{~m}^{2}: 0 \mathrm{spp}\right.$.). The linear model applied was therefore of the form $\mathrm{y}=\beta \cdot \mathrm{x}$; the logarithmic model used was $\mathrm{y}=\alpha \cdot \ln (\beta \mathrm{x}+1)$. To fairly judge the difference between the two models we divided the relative increase in $\mathrm{R}^{2}$ by the relative change in degrees of freedom, leading to an $F$ statistic. $F$ values greater than 1 indicate that model fit has changed more than would be expected by the change in degrees of freedom. We cannot derive an exact significance value for the difference between the models using this $F$ statistic because the individual data points are not statistically independent in our case. But we can use the critical values of the distribution to obtain a general impression of the difference in appropriateness of the two models.

\section{Results}

Overwintering arthropods

Adult representatives of most terrestrial, non-parasitic arthropod phyla and orders occurring in NW-Europe were collected in the cages (Table 1). The number of individuals and species per taxon differed considerably and some taxa were represented poorly, like the species-rich Lepidoptera. At family level absences started to occur. Most of the larger families within the Coleoptera and Araneae were still present but within the Hymenoptera Aculeata, for instance, larger families like Vespidae, Pompilidae and Chrysididae were absent. Some species and higher taxa were collected in rather large numbers, notably Staphylinidae and Diptera-Nematocera. Observations revealed that some species were not trapped very efficiently. Homoptera were frequently seen in the cages but hardly occurred in the traps and in early summer hundreds of dead Diptera-Nematocera were lying on the edges of the side panes where they could not be collected and were subsequently eaten by other taxa.

The species collected not only include species hibernating as adults like many Carabidae and Staphylinidae, but also species overwintering in immature stages. This can 
Table 1 Taxa overwintering in the studied roadside

\begin{tabular}{|c|c|c|c|c|c|c|c|}
\hline & \multicolumn{5}{|l|}{ Cage } & \multirow[t]{2}{*}{ Total } & \multirow[t]{2}{*}{ \# Cages } \\
\hline & 1 & 2 & 3 & 4 & 5 & & \\
\hline \multicolumn{8}{|l|}{ Coleoptera } \\
\hline Carabidae $^{\mathrm{a}}$ & 47 & 60 & 63 & 32 & 40 & 242 & 5 \\
\hline Byrrhidae & 3 & 4 & - & 1 & - & 8 & 3 \\
\hline Cantharidae & - & - & 1 & 10 & - & 11 & 2 \\
\hline Chrysomelidae & - & - & 2 & 1 & - & 3 & 2 \\
\hline Curculionidae $^{\mathrm{a}}$ & 1 & 6 & 6 & 4 & 4 & 21 & 5 \\
\hline Elateridae & 9 & 9 & 12 & 2 & 6 & 38 & 5 \\
\hline Histeridae & 2 & - & - & - & 2 & 4 & 2 \\
\hline Hydrophilidae & 1 & 1 & 1 & 2 & 5 & 10 & 5 \\
\hline Scarabaeidae & - & - & 2 & 1 & 2 & 5 & 3 \\
\hline Silphidae & - & - & 2 & - & 2 & 4 & 2 \\
\hline Staphylinidae & 172 & 202 & 496 & 201 & 386 & 1,457 & 5 \\
\hline Other Coleoptera & 1 & 1 & 2 & 3 & 9 & 16 & 5 \\
\hline \multicolumn{8}{|l|}{ Hymenoptera } \\
\hline Symphyta & - & 1 & - & - & - & 1 & 1 \\
\hline Parasitica & 9 & 4 & 8 & 2 & 15 & 38 & 5 \\
\hline Aculeata & - & 1 & - & 2 & - & 3 & 2 \\
\hline Apidae $^{\mathrm{a}}$ & - & 1 & 1 & - & 4 & 6 & 3 \\
\hline Crabronidae & - & 1 & - & - & - & 1 & 1 \\
\hline Formicidae & 1 & - & 3 & 10 & 3 & 17 & 4 \\
\hline Bethylidae & - & - & - & - & 1 & 1 & 1 \\
\hline Myrmosidae & - & - & - & 1 & - & 1 & 1 \\
\hline \multicolumn{8}{|l|}{ Diptera } \\
\hline Nematocera & $>78$ & $>79$ & $>154$ & $>209$ & $>294$ & $>814$ & 5 \\
\hline Tipulidae & 16 & 10 & 2 & 14 & 31 & 73 & 5 \\
\hline Brachycera & 44 & 47 & 106 & 38 & 36 & 271 & 5 \\
\hline Asilidae & 1 & - & 2 & - & - & 3 & 2 \\
\hline Cyclorrhapha & 8 & 5 & 7 & 7 & 6 & 33 & 5 \\
\hline Syrphidae $\mathrm{a}^{\mathrm{a}}$ & 1 & 2 & - & - & - & 3 & 2 \\
\hline Lepidoptera & 4 & 5 & 3 & 4 & 4 & 20 & 5 \\
\hline Neuroptera (Chrysopidae) & 2 & 5 & - & - & 1 & 8 & 3 \\
\hline Trichoptera & - & - & 1 & - & - & 1 & 1 \\
\hline Orthoptera $^{a}$ & 7 & 22 & - & 1 & 1 & 31 & 4 \\
\hline Heteroptera & 14 & 21 & 10 & 15 & 20 & 80 & 5 \\
\hline Homoptera & 11 & 5 & 17 & 19 & 9 & 61 & 5 \\
\hline Delphacidae $^{\mathrm{a}}$ & 12 & - & - & - & - & 12 & 1 \\
\hline Aphididae & Yes & Yes & - & - & Yes & Yes & 3 \\
\hline Thysanoptera & Yes & Yes & - & Yes & - & Yes & 3 \\
\hline Collembola & $>30$ & $>85$ & $>85$ & $>73$ & $>100$ & $>373$ & 5 \\
\hline Araneae $^{a}$ (epigeic) & 53 & 40 & 60 & 30 & 29 & 212 & 5 \\
\hline Acari & - & Yes & Yes & - & Yes & Yes & 3 \\
\hline Opiliones & - & 4 & - & 4 & - & 8 & 2 \\
\hline Chilopoda & 1 & 6 & 9 & - & - & 16 & 3 \\
\hline Isopoda & 2 & 1 & 3 & 5 & 2 & 13 & 5 \\
\hline Gastropoda & 5 & 13 & 1 & - & 1 & 20 & 4 \\
\hline
\end{tabular}

Presented are the number of individuals emerging from the winter-cut sods in each of the 5 cages. Totals and cage frequency are also given. Numbers for higher level taxa do not include possible lower levels if these are also reported. For details on taxa further identified at the species level we refer to Table 2

${ }^{a}$ For number of species see Table 2 


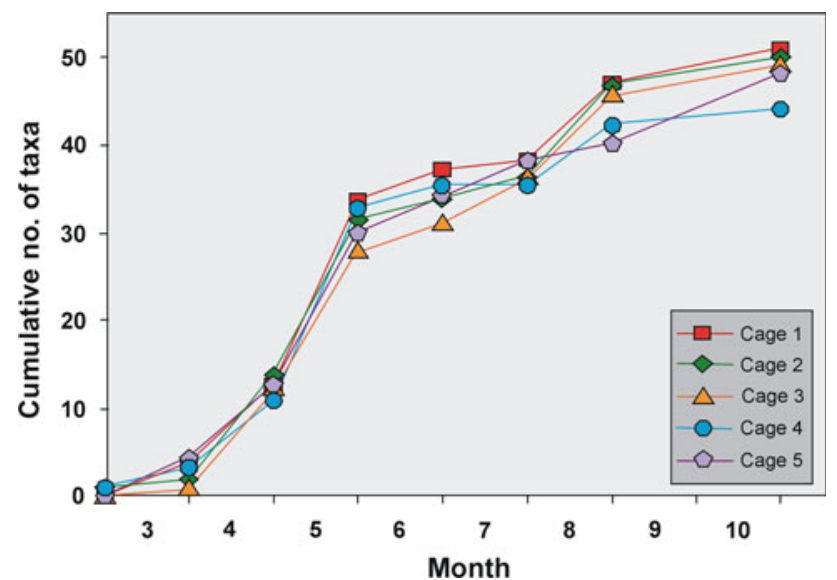

Fig. 2 Cumulative number of taxa identified at the end of each month, in each of the 5 cages containing winter-cut roadside sods

be deducted from the biology of the collected species, but is also illustrated by the continued appearance of additional taxa until the end of summer (Fig. 2).

Most collected species are generalists but less common, more stenotopic species from various orders were present as well. Examples of species characteristic of nutrient poor, sandy grasslands and heathlands are the grasshopper Stenobothrus stigmaticus (Rambur), the digger wasp Didineis lunicornis (Fabricius), the robber fly Machimus cingulatus (Fabricius), the wingless ground beetle Poecilus lepidus (Leske) and the solitary bee Panurgus calcaratus (Scopoli).

\section{Species composition}

The cage results show that many of the Carabidae, Araneae and Curculionidae species recorded in the summer survey, also overwinter in the studied roadside verge (Table 2). For these three groups, the species overlap (relative to the summer catches) amounts to 60-67\%. Rarefaction of the summer sample to correct for differences in sampling intensity, raised the overlap to $68-84 \%$ for these three groups. The alternative of excluding possible summer vagrants (less than four individuals in summer) even raises the overlap to $88 \%$ for Carabidae and $86 \%$ for Curculionidae. Yet, some of the Carabidae and other species that were only caught in scarce amounts during summer did emerge in the cages, sometimes even quite numerous compared to others. We also collected additional species from the cages, species that were not recorded during summer, especially Carabidae (Table 3) and some Araneae.

For Orthoptera the encountered species overlap was $50 \%$, raising slightly after rarefaction of the summer sample. For Apidae, Syrphidae and Delphacidae/Cercopidae the overlap is rather low (20\% or less). Rarefaction or removing possible vagrants increases the overlap, but for

Table 2 Comparison of the overwintering arthropod composition with the summer survey

\begin{tabular}{|c|c|c|c|c|c|c|c|c|c|c|c|c|c|c|c|}
\hline & \multicolumn{2}{|c|}{ Individuals } & \multicolumn{13}{|l|}{ Species } \\
\hline & \multirow[t]{2}{*}{ Winter } & \multirow[t]{2}{*}{ Summer } & \multirow{2}{*}{$\begin{array}{l}\text { Winter } \\
\mathrm{w}\end{array}$} & \multicolumn{4}{|c|}{ Summer (all) } & \multicolumn{4}{|c|}{ Rarefied summer } & \multicolumn{4}{|c|}{ w/o possible vagrants } \\
\hline & & & & $\mathrm{s}$ & $\mathrm{t}$ & $\mathrm{O}$ & $\mathrm{O} / \mathrm{s}$ & s & $\mathrm{t}$ & $\mathrm{O}$ & $\mathrm{O} / \mathrm{s}$ & $\mathrm{s}$ & $\mathrm{t}$ & $\mathrm{O}$ & $\mathrm{O} / \mathrm{s}$ \\
\hline Carabidae & 242 & 2,417 & 26 & 30 & 38 & 18 & $60 \%$ & 18.0 & 29.0 & 15.0 & $83 \%$ & 27 & 28 & 15 & $88 \%$ \\
\hline Araneae $^{\mathrm{a}}$ & 69 & 277 & 15 & 18 & 22 & 11 & $61 \%$ & 9.9 & 18.3 & 6.7 & $67 \%$ & 7 & 17 & 5 & $71 \%$ \\
\hline Curculionidae & 21 & 162 & 8 & 12 & 12 & 8 & $67 \%$ & 6.3 & 9.0 & 5.3 & $84 \%$ & 7 & 9 & 6 & $86 \%$ \\
\hline Orthoptera $^{\mathrm{b}}$ & 10 & Yes & 3 & 6 & 6 & 3 & $50 \%$ & 4.0 & 4.7 & 2.3 & $58 \%$ & 6 & 6 & 3 & $50 \%$ \\
\hline Apidae $^{\mathrm{c}}$ & 6 & 30 & 3 & 10 & 11 & 2 & $20 \%$ & 4.2 & 6.2 & 1.0 & $(24 \%)$ & 3 & 5 & 1 & $(33 \%)$ \\
\hline Syrphidae $^{\mathrm{d}}$ & 3 & 24 & 2 & 8 & 9 & 1 & $13 \%$ & 1.9 & 2.9 & 0.9 & $(47 \%)$ & 3 & 4 & 1 & $(33 \%)$ \\
\hline Delphacidae $^{\mathrm{e}}$ & 12 & 85 & 2 & 5 & 6 & 1 & $20 \%$ & 2.4 & 3.4 & 1.0 & $(42 \%)$ & 2 & 3 & 1 & $(50 \%)$ \\
\hline
\end{tabular}

On the left the number of individuals are compared. On the right the number of species, using either all summer species, after rarefaction of the summer catches, or after removing possible summer vagrants. $w$ winter; $s$ summer; $t$ total; $O$ overlap. Percentage species overlap is calculated relative to the number of species in summer $(\mathrm{O} / \mathrm{s})$. Alternative measures of similarity can be calculated from the table: Jaccard index is obtained by dividing $\mathrm{O}$ by $\mathrm{t}$ while Sørensen similarity (equal to the Bray-Curtis measure for this presence-absence approach) can be obtained from $2 \cdot \mathrm{O} /$ $(\mathrm{s}+\mathrm{w})$

${ }^{a}$ Excluding the Linyphiidae and Salticidae (not identified at the species level)

${ }^{\mathrm{b}}$ No summer counts available, only density estimates based on sound observations. Rarefaction based on estimated numbers of individuals for density classes: $1=1,2=3,3=10,4=30,5=100,6=300$ individuals. No species in lowest density class at the study site, so no suspected summer vagrants

${ }^{c}$ Excluding the Honeybee: Apis mellifera (Linnaeus)

d Excluding five species from the summer catches that overwinter as aquatic larvae only

e Including also Cercopidae. The one species overlapping between summer and winter concerns the species most common in summer 
Table 3 Overwintering Carabidae species compared to the summer season pitfall catches

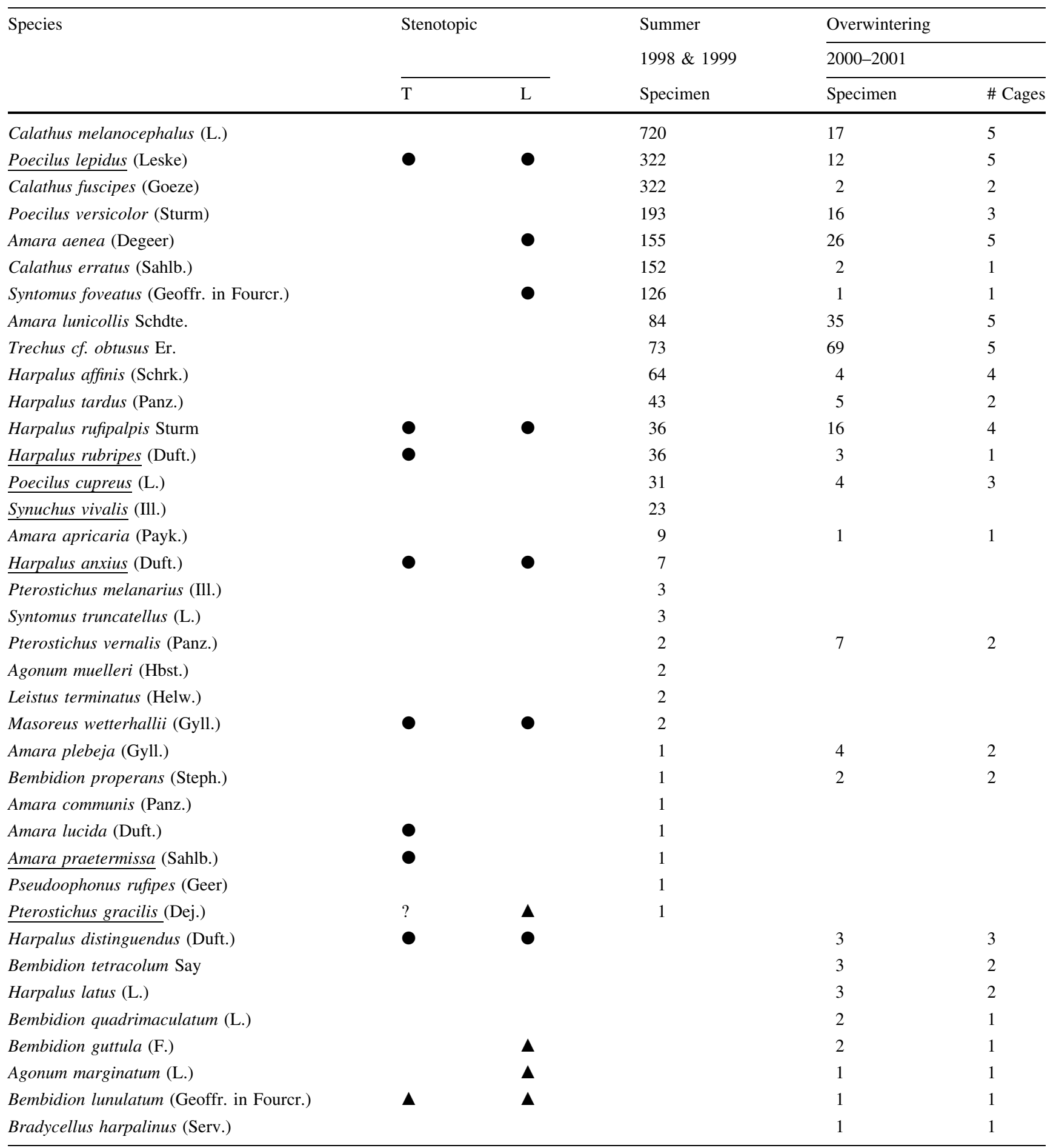

Presented overwintering data are the number of individuals caught in the 5 cages with winter-cut roadside sods collectively, as well as the number of cages in which the species was encountered. Summer data comprise the individuals caught during two growing seasons using 5 pitfalls. Underlined species are declining in the Netherlands, Belgium and Denmark (Desender and Turin 1989; some of these may still be common nonetheless). Whether or not a species can be considered stenotopic (see "Methods") is indicated according to Turin 2000 (T) or Lindroth 1949 (L). Symbols: - stenotopic from dry habitats, $\boldsymbol{\Delta}$ stenotopic from wet habitats

these groups the summer data is not very well suited for rarefaction or deleting possible vagrants due to their high mobility and/or the low numbers captured.
Of the seven declining Carabidae species caught during the summer surveys, three also emerged in the cages (Table 3). Of the remaining four, two had been represented 

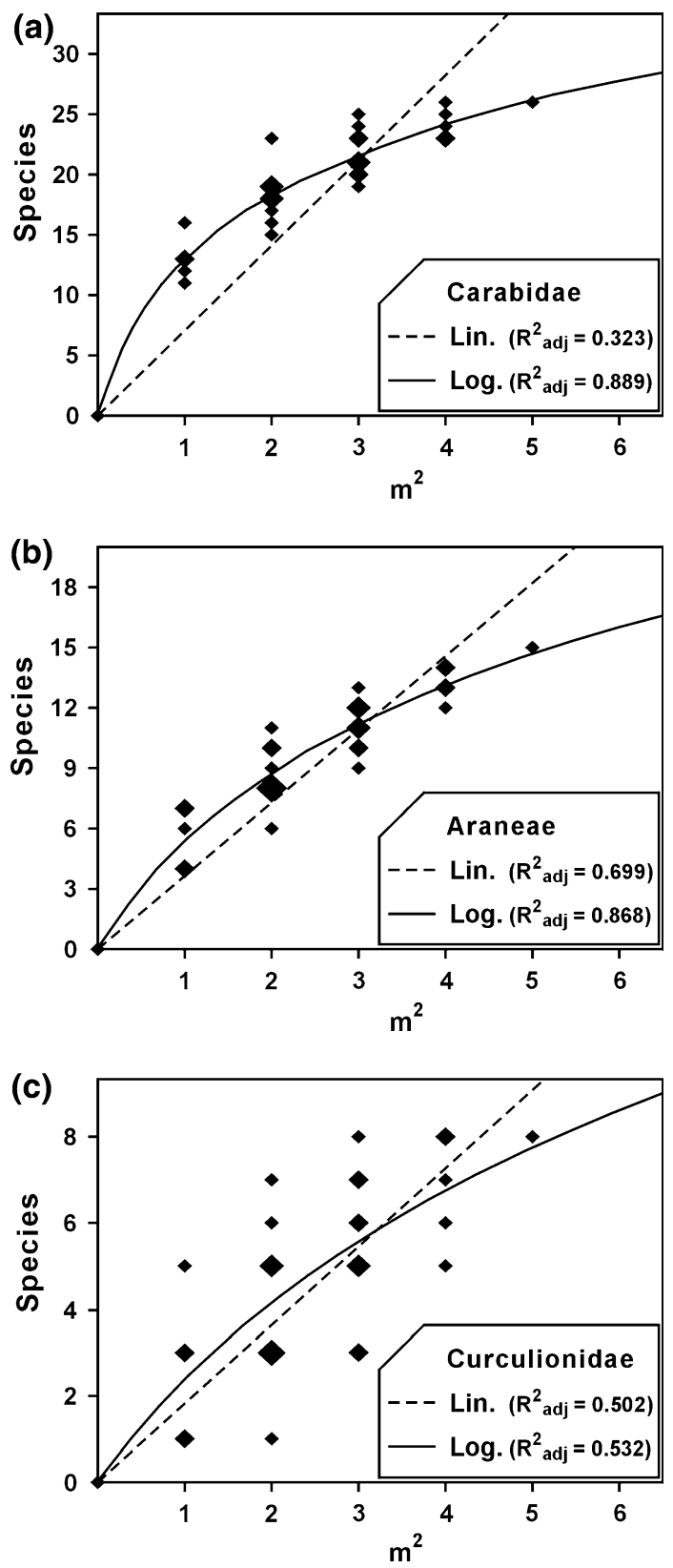

Fig. 3 Rarefied overwintering data for: a Carabidae, b Araneae, and c Curculionidae. Presented are the fitted curves (linear and logarithmic) and their $R_{a d j}^{2}$ values. Symbol size of data-points reflects the number of identical data points at that specific coordinate (range 1-5)

by only one individual in the summer survey. Of the stenotopic species caught during summer approximately $50 \%$ were present in the overwintering cages, regardless of whether Turin's (2000) or Lindroth's (1949) classification of biotope specificity is used (Table 3 ). In this case also, most of the species 'missing' in the cages were rare recordings during summer (possible vagrants). Of the eight species only found in the cages, two are stenotopic according to Turin, and four according to Lindroth. Surprisingly, of the four 'cage-only' species classified as stenotopic by Lindroth, three prefer wet biotopes. However, two of these (very small Bembidion species with only one or two individuals each) might be accidental cageinvasions. The grasshopper Stenobothrus lineatus (Panzer) and the solitary bee Andrena ovatula (Kirby), both vulnerable species in the Netherlands (Odé et al. 1999; Peeters and Reemer 2003), were recorded in low densities during the summer survey but did not emerge in the cages.

In general, Carabidae species that were more abundant in the summer survey, were indeed more numerous in the winter sample and visa-versa (Spearman's $\rho=0.442$; $\mathrm{n}=38$; one-sided $P=0.003$ ). For the Araneae such a positive relationship is also present, but significant only if the analysis is restricted to the overlapping species ( $\rho=0.581 ; \mathrm{n}=11 ; P=0.03$ ). For the Curculionidae the number of species is quite low, but nevertheless an indication exists for a positive correlation $(\rho=0.458 ; \mathrm{n}=12$; $P=0.07)$, partly because the species that was most common in summer also appeared to be the most common in the overwintering cages.

\section{Comprehensiveness of winter assessment}

For both the Carabidae (Fig. 3a) and Araneae (Fig. 3b) the logarithmic models fitted the rarefied winter data better than the linear model $\left(\mathrm{F}_{[1,30]}=159.5\right.$ for Carabidae and 40.55 for Araneae; with critical values for $\alpha=0.05$ at 4.17, for $\alpha=0.01$ at 7.56, and for $\alpha=0.0001$ at 20.1). This indicates a clear saturation of species numbers within the surface area of sods used $\left(0-5 \mathrm{~m}^{2}\right)$ although the levelling-off is less pronounced for the Araneae.

The Curculionidae (Fig. 3c) show relatively low fit values for both models due to the large amount of scatter which, in turn, is caused by the low number of species caught. Because of this there is little difference between the fit of the two models $\left(\mathrm{F}_{[1,30]}=2.98\right.$, with the critical value for $\alpha=0.10$ at 2.88), indicating that for this group there is no clear sign of species saturation yet.

\section{Discussion}

The roadside verge appears to be used as an overwintering site for a large number of arthropod groups and a high level of overlap was demonstrated between the overwintering species and the species encountered in a common biosurvey in summer. This holds particularly for the Carabidae, Araneae and Curculionidae (and to a lesser extent also the Orthoptera). Although winter sampling was limited to $5 \mathrm{~m}^{2}$ of soil sods, a large proportion of the overwintering species has likely been identified, as clear levelling-off could be demonstrated in some of the rarefaction curves (Fig. 3). Particularly for the Carabidae and Araneae these 
curves suggest that species numbers would probably not have been much higher with larger sample sizes, which is in accordance with the clear overlap in species composition between overwintering species and the species observed during summer surveys for these groups (Table 3). For the Curculionidae, species saturation could not be clearly demonstrated due to the low number of species, but also for this group confidence in the winter data is strengthened by the similarity in summer and winter composition, which was of comparable magnitude to that of the Carabidae.

Our results seem to validate summer sampling (the most common method to assess arthropod conservation value) as an effective bio-survey. However, this is only true because in our case overwintering was positively confirmed for a large proportion of the species caught in summer. Without such confirmation, sampling under optimum conditions and restricted to particular life history stages may still not provide us with a correct indication of the actual habitat value of a site (Dover and Settele 2009). An interesting observation on the efficiency of summer sampling can be made if we examine the species numbers after rarefication of the summer survey to the size of the winter sample (Table 2). For Carabidae, Araneae and Curculionidae the winter sampling of soil sods then appears to have been more effective than the summer survey (26 vs. 18,15 vs. 9.9 and 8 vs. 6.3 species, respectively). It is only because large numbers of (active) individuals can be trapped with limited effort that summer surveys appear more effective for these groups.

For the species that also turned up in the winter survey (the overlap) the summer survey is indeed validated. Yet the reverse conclusion, that taxa must have been coincidental or seasonal vagrants if only present in the summer survey, is not necessarily true. For these species the situation is unclear since emerging individuals only reveal methodological success. Absences from the winter cages can have different explanations than the site being unsuitable for successful overwintering. Various methodological aspects may be responsible.

First of all, cage induced circumstances may have prohibited individuals to survive and reach adulthood (Southwood and Siddorn 1965). Secondly, trapping in the cage may not have been fully efficient and this may cause some species to have been missed. Thirdly, sample size may not have been sufficient and some species may not have been included in the sampled sods. This particularly holds for rare species and for species overwintering in clusters, which is not uncommon and occurs in many arthropod groups (Allee 1931; Thiele 1977; Leather et al. 1993; Andersen 2011). For such species, larger sample sizes may be needed to establish their presence. A final reason may be the deliberate selection of homogeneous vegetation for sampling of sods. Many species rather prefer sites with more variation for overwintering; e.g. at the boundary between vegetation types, in heterogeneous patches near disturbances, under accumulated litter, near the edge of a ditch, near tussocks or molehills, etc. (Dennis et al. 1997; Woodcock et al. 2007).

From cage observations and the ecology of the studied taxa, we can often deduce whether the absence of species is mainly due to actual unsuitability of the site or to methodological circumstances. Many overwintering Orthoptera may have been missed due to methodological problems. Of several tens of individuals in the cages in spring, only five reached adulthood. Juveniles (which could not yet be identified at the species level) often climbed to the cage roof and fell into the funnel traps (recorded as Orthoptera in Table 1, but not identified at species level in Table 2). For species occurring in low densities, like Stenobothrus lineatus, sample size (area of sods) may have been limiting as well. For Delphacidae/Cercopidae and other Homoptera the trapping methods in the cages were rather inefficient. Many individuals were observed in the cages but relatively few were actually collected.

The low correspondence between summer and winter catches for Syrphidae and Apidae can partly be ascribed to the large individual dispersal ranges of these flying flowervisitors, which may give them a high chance of detection in summer. For the Syrphidae for instance, mainly very common and mobile species were recorded in summer; these may well have been seasonal or accidental visitors. Rarefaction of the summer sample (with strong effects for both Syrphidae and Apidae) might have compensated for this, but still did not lead to satisfactory levels of species cross-over. Apparently, site unsuitability or other ecological aspects also play a role here. For the Syrphidae only few of the species observed in summer actually hibernate as adults (e.g. Eristalis tenax (Linnaeus) and Episyrphus balteatus (De Geer)). The others hibernate in immature stages near the oviposition site. The absence of most of these is understandable, as their larvae live as (semi-)aquatic filterfeeders, as predators of aphids in trees, or in mouldered wood or dung (Rotheray 1993). For many Apidae species efficient winter sampling is complicated as nesting and therefore overwintering is highly clustered (Michener et al. 1958; Batra 1978; Rosenheim 1990; Westrich 1990). Another complication for some species is their use of so called partial habitats, which is particularly well described for bees (Westrich 1996). For such species, reproduction requirements (e.g., nest site, nesting material and food for brood provisioning), can only be met by spatially separated areas lying within limited distances of each other.

For some species groups, particularly Carabidae, the overwintering species composition appeared to be more than just a subset of the summer species composition, as overwintering species were found that were not recorded in 
the summer survey. A remarkably large proportion of the additional Carabidae species was characteristic of wet conditions (Table 3). As the studied site lies near the river Rhine, not far from the highest inundation levels, some of these additional 'wet' species might be species evading flooding or overwintering away from water bodies. The single specimen of Pterostichus gracilis (Dejean), the only 'wet' species recorded in the summer survey, was collected in April and may well fall in this category (possibly concerning an individual that had just left its overwintering site). The presence of such species could therefore indicate seasonal occurrence but, unlike the farmland situation described by Sotherton $(1984,1985)$, this would concern a winter instead of a summer influx. Migration to specific and distant winter biotopes is mentioned by Van Huizen (1977) for Amara plebeja (Gyllenhal), which is said to retreat to woodlands in autumn and hibernate there while recolonising grasslands during the growing season. But as this species also emerged from the grassland sods in the cages during our study this migratory behaviour is probably not strongly developed.

The results of this study show that overwintering in roadside verges is not confined to species that overwinter as adults. The emergence of species that overwinter as eggs (e.g. Orthoptera) or in larval stages at the oviposition site (e.g., Apidae and Crabonidae) implies that verges can also be used for actual reproduction.

Distinguishing between the actual source or sink character of our site is not as clear-cut as it may seem in theory. For instance Pulliam (1988) argued that it might be common for species to have a large fraction of their individuals occurring in "sink" habitats (maintained by surplus individuals from, possibly even small, source habitats) and that this may be ecologically stable. Watkinson and Sutherland (1995) showed that sometimes populations may appear as sinks (mortality exceeding reproduction) despite these populations being entirely viable in the absence of immigration. Such "pseudo-sinks" occur when immigration into the population reduces reproduction or increases mortality due to density dependent effects, resulting in a population that appears to be maintained by this immigration.

Such arguments imply that even if detailed quantitative data on reproduction, mortality and immigration would have been available, we would not be able to decide from this data on the actual character of our site in terms of source, sink or pseudo-sink, neither would this reveal the ecological relevance of the site in a meta-population context. However, if a sink is simply defined as an area where factors are insufficient for a species to carry out its life history (Pulliam 1988), we can conclude that the study site clearly did not act only as a sink, as it apparently provides resources for the persistence of a range of arthropod species and functions as a year-round habitat.
It could be argued that the studied roadside concerns a relatively wide verge, receiving a more conservationfriendly form of management than most other verges. However, roadsides are quite often much wider than the first one or two meters many people usually visualise (Schaffers 2000). Particularly along highways and motorways the habitat managed by road authorities is often several meters wide (even up to twenty or more) and generally receives an extensive form of management (Schaffers 2000). Nevertheless, more intensively managed roadside verges should be studied as well to see if also they have a similar capacity to support insect overwintering.

The results of this study demonstrate that roadside verges are used as overwintering sites by many arthropod taxa and that verges can also be used for actual reproduction. Apparently, the roadside occurrence of various arthropod species, including stenotopic and declining ones, is not merely seasonal or incidental, and roadside verges do not act as a sink only. Many species are capable of completing their entire life cycle in the roadside habitat, and in some cases the roadside verge may even act as a refuge (Eversham and Telfer 1994). These results imply that the ecological importance often attributed to roadside verges should clearly be taken seriously, at least as far as the habitat function for arthropods is concerned. Roadside verges truly are capable of performing conservation objectives.

Acknowledgments We are much indebted to Jinze Noordijk (European Invertebrate Survey-Netherlands) and two anonymous referees for helpful comments on the manuscript. This study was financially supported by the DVS Centre for Transport and Navigation of the Dutch Ministry of Infrastructure and the Environment.

Open Access This article is distributed under the terms of the Creative Commons Attribution Noncommercial License which permits any noncommercial use, distribution, and reproduction in any medium, provided the original author(s) and source are credited.

\section{References}

Allee WC (1931) Animal aggregations, a study in general sociology. The University of Chicago press, Chicago

Andersen J (2011) Winter quarters of wetland ground beetles (Coleoptera, Carabidae) in South Scandinavia. J Insect Conserv. doi:10.1007/s10841-011-9378-7

Anonymus (1984) Besluit van de Vlaamse Regering van 27 juni 1984 houdende maatregelen inzake natuurbehoud op de bermen beheerd door publiekrechtelijke rechtspersonen. ID 1007216. Belgisch Staatsblad (Belgian Official Gazette) October 2, 1984: 13392

Batra SWT (1978) Aggression, territoriality, mating and nest aggregation of some solitary bees (Hymenoptera: Halictidae, Megachilidae, Colletidae, Anthophoridae). J Kans Entomol Soc 51:547-559

DeMers MN (1993) Roadside ditches as corridors for range expansion of the western harvester ant (Pogonomyrmex occidentalis Cresson). Landsc Ecol 8:93-102 
Dennis RLH (2001) Progressive bias in species status is symptomatic of fine-grained mapping units subject to repeated sampling. Biodivers Conserv 10:483-494

Dennis P, Young MR, Howard CL, Gordon IJ (1997) The response of epigeal beetles (Col: Carabidae, Staphylinidae) to varied grazing regimes on upland Nardus stricta grasslands. J Appl Ecol $34: 433-443$

Dennis RLH, Shreeve TG, Sheppard DA (2007) Species conservation and landscape management: a habitat perspective. In: Stewart AJA, New TR, Lewis OT (eds) Insect conservation biology. Cabi, Wallingford, pp 92-126

Desender K, Turin H (1989) Loss of habitats and changes in the composition of the ground- and tiger beetle fauna in four WestEuropean countries since 1950 (Coleoptera: Carabidae, Cicindelidae). Biol Conserv 48:277-294

Desender K, Dekoninck W, Dufrêne M, Maes D (2010) Changes in the distribution of carabid beetles in Belgium revisited: Have we halted the diversity loss? Biol Conserv 143:1549-1557

Dover J, Settele J (2009) The influences of landscape structure on butterfly distribution and movement: a review. J Insect Conserv 13:3-27

Dowdeswell WH (1987) Hedgerows and verges. Allen \& Unwin, London

Eversham BC, Telfer MG (1994) Conservation value of roadside verges for stenotopic heathland Carabidae: corridors or refugia? Biodivers Conserv 3:538-545

Geiger F, de Snoo GR, Berendse F et al (2010) Landscape composition influences farm management effects on farmland birds in winter: A pan-European approach. Agr Ecosyst Environ 139:571-577

Hurlbert SH (1971) The nonconcept of species diversity: a critique and alternative parameters. Ecology 52:577-586

Keizer PJ, van den Hengel LC, Groshart C (2006) Leidraad beheer groenvoorzieningen. DWW-2006-039. Rijkswaterstaat, Dienst Weg-en Waterbouwkunde, Delft

Koivula MJ (2005) Effects of forest roads on spatial distribution of boreal Carabid beetles (Coleoptera: Carabidae). Coleopt Bull 59:465-487

Koivula MJ, Kotze DJ, Salokannel J (2005) Beetles (Coleoptera) in central reservations of three highway roads around the city of Helsinki, Finland. Ann Zool Fenn 42:615-626

Kotze DJ, Brandmayr P, Casale A et al (2011) Forty years of carabid beetle research in Europe-from taxonomy, biology, ecology and population studies to bioindication, habitat assessment and conservation. In: Kotze DJ, Assmann T, Noordijk J, Turin H, Vermeulen R (eds) Carabid beetles as bioindicators - biogeographical, ecological and environmental studies. ZooKeys 100:55-148

Le Viol I, Julliard R, Kerbiriou C, de Redon L, Carnino N, Machon N, Porcher E (2008) Plant and spider communities benefit differently from the presence of planted hedgerows in highway verges. Biol Conserv 101:1581-1590

Leather SR, Walters KFA, Bale JS (1993) The ecology of insect overwintering. University press, Cambridge

Legendre P, Legendre L (1998) Numerical ecology, 2nd English edn. Elsevier, Amsterdam

Lindroth CH (1949) Die Fennoskandischen Carabiden III, Algemeiner Teil. Göteborg

Michener CD, Lange RB, Bigarella JJ, Salamuni R (1958) Factors influencing the distribution of bees' nests in earth banks. Ecology 39:207-217

Munguira ML, Thomas JA (1992) Use of road verges by butterfly and burnet populations, and the effect of roads on adult dispersal and mortality. J Appl Ecol 29:316-329

Noordijk AJ (2009) Arthropods in linear elements-occurrence, behaviour and conservation management. Dissertation, Wageningen University
Noordijk J, Raemakers IP, Schaffers AP, Sýkora KV (2009) Arthropod richness in roadside verges in the Netherlands. Terr Arthropod Rev 2:63-76

Odé B, Keijl GO, van Ommering G (1999) Threatened and vulnerable Orthoptera in the Netherlands. Commentary on the Red-list. IKC Natuurbeheer, Wageningen

Peeters TMJ, Reemer M (2003) Threatened and extinct species in the Netherlands (Apidae s.1.). Base report with proposed Red-list. Stichting European Invertebrate Survey, The Netherlands

Pulliam HR (1988) Sources, sinks and population regulation. Am Nat 132:652-661

Ries L, Debinski DM, Wieland ML (2001) Conservation value of roadside prairie restoration to butterfly communities. Conserv Biol 15:401-411

Rosenheim JA (1990) Density dependent parasitism and the evolution of aggregated nesting in solitary Hymenoptera. Ann Entomol Soc Am 83:277-286

Rotheray GE (1993) Colour guide to hoverfly larvae (Diptera, Syrphidae). Dipter Dig (1st series) 9:1-156

RWS (2004) Nota mobiliteit (policy document on traffic and infrastructure management). Dutch ministry of Transport, Public works, and Water management, Delft

Samways MJ, Osborn R, Carliel F (1997) Effect of a highway on ant (Hymenoptera: Formicidae) species composition and abundance, with a recommendation for roadside verge width. Biodivers Conserv 6:903-913

Samways MJ, McGeoch MA, New TR (2010) Insect conservation, a handbook of approaches and methods. Oxford University press, Oxford

Schaffers AP (2000) Ecology of roadside plant communities. Dissertation, Wageningen University

Schaffers AP, Raemakers IP, Sýkora KV, ter Braak CJF (2008) Arthropod assemblages are best predicted by plant species composition. Ecology 89:782-794

Schaminée JHJ, Stortelder AHF, Weeda EJ (1996) Vegetation classification of the Netherlands, part 3. Opulus Press, Uppsala

Sotherton NW (1984) The distribution and abundance of predatory arthropods overwintering on farmland. Ann Appl Biol 105:423429

Sotherton NW (1985) The distribution and abundance of predatory Coleoptera overwintering in field boundaries. Ann Appl Biol 106:17-21

Southwood TRE, Henderson PA (2000) Ecological methods. Blackwell Science, Oxford

Southwood TRE, Siddorn JW (1965) The temperature beneath insect emergence traps of various types. J Anim Ecol 34:581-585

Speight MR, Hunter MD, Watt AD (2008) Ecology of insects, concepts and applications, 2nd edn. Wiley-Blackwell, Chichester

Stoate C, Boatman ND, Borralho RJ, Carvalho CR, De Snoo GR, Eden P (2001) Ecological impacts of arable intensification in Europe. J Environ Manage 63:337-365

Sýkora KV, de Nijs LJ, Pelsma TAHM (1993) Plant communities of Dutch roadside verges. KNNV, Utrecht

Tauber MJ, Tauber CA (1976) Insect seasonality: diapause maintenance, termination, and postdiapause development. Ann Rev Entomol 21:81-107

Thiele HU (1977) Carabid beetles in their environment. A study on habitat selection and adaptations in physiology and behaviour. Zoophysiology and Ecology 10. Springer, Berlin

Thomas CFG, Parkinson L, Griffiths GJK, Fernandez Garcia A, Marshall EJP (2001) Aggregation and temporal stability of carabid beetle distributions in field and hedgerow habitats. J Appl Ecol 38:100-116

Turin H (2000) The Dutch groundbeetles, distribution and ecology. Nederlandse Fauna 3. Nationaal Natuurhistorisch Museum Naturalis, KNNV Uitgeverij \& EIS-Nederland, Leiden 
Van Huizen T (1977) The significance of flight activity in the life cycle of Amara plebeja Gyllh. (Coleoptera, Carabidae). Oecologia 29:27-41

Vermeulen HJW (1993) The composition of the carabid fauna on poor sandy roadside verges in relation to comparable open areas. Biodivers Conserv 2:331-350

Vermeulen HJW (1994) Corridor function of a road verge for dispersal of stenotopic heathland ground beetles (Carabidae). Biol Conserv 69:339-349

Watkinson AR, Sutherland WJ (1995) Sources, sinks and pseudosinks. J Anim Ecol 64:126-130

Way JM (1977) Roadside verges and conservation in Britain: a review. Biol Conserv 12:65-74
Westrich P (1990) Die Wildbienen Baden-Württembergs. Allgemeiner Teil, Ulmer

Westrich P (1996) Habitat requirements of the central European bees and the problems of partial habitats. In: Matheson A, Buchmann SL, O'Toole C, Westrich P, Williams IH (eds) The conservation of bees. 1-16. Academic Press, London

Woodcock BA, Potts SG, Westbury DB, Ramsay AJ, Lambert M, Harris SJ, Brown VK (2007) The importance of sward architectural complexity in structuring predatory and phytophagous invertebrate assemblages. Ecol Entomol 32:302-311

Zwaenepoel A (1998) Werk aan de berm! Handboek botanisch bermbeheer. Stichting Leefmilieu, Antwerpen 